Int. J. Electrochem. Sci., 12 (2017) 9736 - 9746

\title{
Preparation of Porous Carbon-Manganese Dioxide Nanocomposite for Sensitive Determination of Cadmium Ion
}

\author{
Hua Liu ${ }^{1}$, Xiaolin Yu ${ }^{l}$, Huafeng Chen ${ }^{1}$ and Yanhong Liu ${ }^{2, *}$ \\ ${ }^{1}$ Department of Biomedical Engineering,Guangdong Pharmaceutical University, Guangzhou 510006, \\ China \\ ${ }^{2}$ Department of Endocrinology, The Second People's Hospital of Hengshui, Hengshui 053000, China \\ *E-mail: hongyanliu_ss@qq.com
}

doi: $10.20964 / 2017.10 .35$

Received: 29 June 2017 / Accepted: 6 August 2017 / Published: 12 September 2017

\begin{abstract}
A cost-effective pyrolysis carbonization, together with a subsequent alkali activation, was performed for the preparation of activated porous carbons (APCs) with meso-/macropores and micropores. This was followed by electrodepositing manganese oxide nanostructures onto the as-prepared APC substrate with a constant anodic current. In addition, as studied by square-wave voltammetry (SWV) measurements, $\mathrm{MnO}_{2}$-activated carbon (AC) was utilized for the detection of cadmium(II) (Cd(II)), where the metal ions accumulated on $\mathrm{MnO}_{2}-\mathrm{AC}$. Through the modification of the electrode surface and the optimization of relevant parameters, the behaviour of $\mathrm{MnO}_{2}-\mathrm{AC}$ reached an optimum level in this study
\end{abstract}

Keywords: Activated porous carbon; Manganese oxide; Cadmium ion; Square wave voltammetry;

\section{FULL TEXT}

(C) 2017 The Authors. Published by ESG (www.electrochemsci.org). This article is an open access article distributed under the terms and conditions of the Creative Commons Attribution license (http://creativecommons.org/licenses/by/4.0/). 